Part of Journal of Research of the National Bureau of Standards, Volume 21, July 1938

\title{
DETERMINATIONS OF OXYGEN IN ALLOY STEELS
}

\author{
By John G. Thompson and Vernon C. F. Holm
}

\section{ABSTRACT}

The oxygen contents of many types of alloy steels can be determined with accuracy by either the vacuum-fusion or the hydrogen-reduction procedure. The presence of the common alloying elements does not interfere with the operation of either method. The limitations of both methods are essentially the same for alloy steels as for plain carbon steels.

\section{CONTENTS}

I. Introduction

II. Purpose of the investigation

III. Experimental results.

IV. Summary

V. References

\section{INTRODUCTION}

The determination of the oxygen contained in any specimen of ferrous material is a complex problem because of the number of forms and combinations of oxygen that are encountered. Even the simplest of plain carbon steels may contain oxygen in three distinct states (a) gaseous compounds, $(b)$ solid solution, and (c) inclusions. The amounts of the first two usually are of minor importance, the bulk of the oxygen occurring as simple or complex inclusions of $\mathrm{FeO}, \mathrm{MnO}$, $\mathrm{SiO}_{2}$, and $\mathrm{Al}_{2} \mathrm{O}_{3}$. The relative proportions of the four oxides and their states of combination depend on the practice employed in the melting and refining of the steel. Each of these oxides and combinations presents different analytical problems, and the matter becomes increasingly complicated in alloy steels because of the probable occurrence of additional oxide compounds of the alloying elements.

The application of the various methods to the analysis of plain carbon steels has been extensively investigated, but the accuracy of the various methods, even for the analysis of simple steels, is still a controversial question in some respects. The report of the recent cooperative study of methods for the determination of oxygen in steel [1] ${ }^{1}$ showed, by means of agreement in results obtained by different methods, that accurate determinations of $\mathrm{Al}_{2} \mathrm{O}_{3}$ in simple steels can be made by several methods; the accuracy of determinations of $\mathrm{SiO}_{2}$ varies with the composition of the silicate inclusions; reliable

\footnotetext{
1 The numbers in brackets here and throughout the text refer to the list of references at the end of the
} paper. 
methods for the determination of $\mathrm{FeO}$ and $\mathrm{MnO}$ are not yet available; accurate determinations of total oxygen, without identification of the various oxides, can be obtained from many plain carbon steels by the vacuum-fusion procedure. This procedure may yield low results if the sample has a high content of manganese or other volatile metal, and particularly if large or refractory inclusions also are present. Recent work in this laboratory [2] has shown that a modified hydrogen-reduction method also yields accurate results for the total oxygen content of many plain carbon steels, although low recoveries of oxygen may be obtained if high contents of $\mathrm{Al}_{2} \mathrm{O}_{3}$ or $\mathrm{FeO}$ are present.

The determination of oxygen in alloy steels has received relatively little attention. A few determinations have been reported but no attempt has been made to define their accuracy, as was done for determinations on simple steels in the cooperative analysis. Ericson and Benedicks [3], in 1931, reported that satisfactory determinations of the oxygen content of low-carbon steel were obtained by means of their vacuum-fusion procedure, in spite of the presence in the crucible of alloying elements in amounts as follows: Up to 50 percent of chromium, 10 percent of tungsten or molybdenum, 2.5 percent of vanadium, and 1 percent of titanium. This lack of interference, by metallic alloying elements, in the determination of the oxides in a simple steel does not necessarily mean that the analysis of alloy steels would be equally satisfactory. Alloy steels may contain oxides of the alloying elements in addition to $\mathrm{FeO}, \mathrm{MnO}, \mathrm{SiO}_{2}$, and $\mathrm{Al}_{2} \mathrm{O}_{3}$, and it is not definitely known whether these oxides of the alloying elements are more or less refractory than the oxides and combinations ordinarily encountered in simple steels.

Hamilton [4] reported that results for oxygen in certain alloy steels, by the vacuum-fusion method, were satisfactorily reproducible and could be correlated with certain properties of the steels. Reproducibility of results, however, does not establish their accuracy. The recent cooperative study [1] revealed a number of instances where different analysts using the same method could each duplicate their own results with satisfactory precision, but the reproducible results of one analyst were not in satisfactory agreement with the reproducible results of another. The best criterion of accuracy that is available at present, in the determination of oxygen, is agreement of results obtained by different methods of analysis.

\section{PURPOSE OF THE INVESTIGATION}

The present investigation is an attempt to establish the accuracy of oxygen determinations in alloy steels through the use of two independent methods of analysis. Residue methods were eliminated from consideration for two reasons: (a) Uncertainty of their reliability in the determination of oxides in simple steels and (b) uncertainty of their application to the determination of the other oxides presumably present in alloy steels. The two methods that were selected were the vacuum-fusion method, essentially as described by Vacher and Jordan [5], and a modification of the hydrogen-reduction method, essentially as described by Brower, Larsen, and Shenk [6]. In the vacuum-fusion procedure the oxides in the molten sample are reduced by carbon at $1,650^{\circ} \mathrm{C}$, and the gaseous products of the reduc- 
tion reactions are subsequently determined. In the modified hydrogen-reduction procedure the finely milled sample is treated with hydrogen, first at about $500^{\circ} \mathrm{C}$ to remove the surface film of oxides and moisture, and finally at $1,200^{\circ} \mathrm{C}$ to reduce the dissolved or "body" oxides of the sample. The products of the latter reduction reactions are subsequently recovered and determined.

The results obtained in the cooperative analysis [1] and in additional experiments in this laboratory [2] showed that both procedures determined total oxygen in simple steels and that, when determinations by the two methods were in agreement, the indicated values were close approximations of the true oxygen content of the steel. Each method has its limitations, but these are not the same for both. Consequently, in the analysis of alloy steels or other steels of unknown oxygen content, agreement in results obtained by these two independent methods is strong evidence of accuracy, and failure to obtain agreement indicates that one or the other method is in error.

\section{EXPERIMENTAL RESULTS}

Determinations of oxygen, by both the vacuum-fusion and hydrogen-reduction methods, were made on 14 alloy steels covering a wide range of composition of commercially important materials. Nine of the samples were prepared from material constituting some of the Bureau's Standard Samples and several additional samples of 18 chromium-8 nickel steel were included because of the current interest in this particular composition. The compositions of the steels are indicated in table 1.

TABLE 1.-Composition of alloy steels

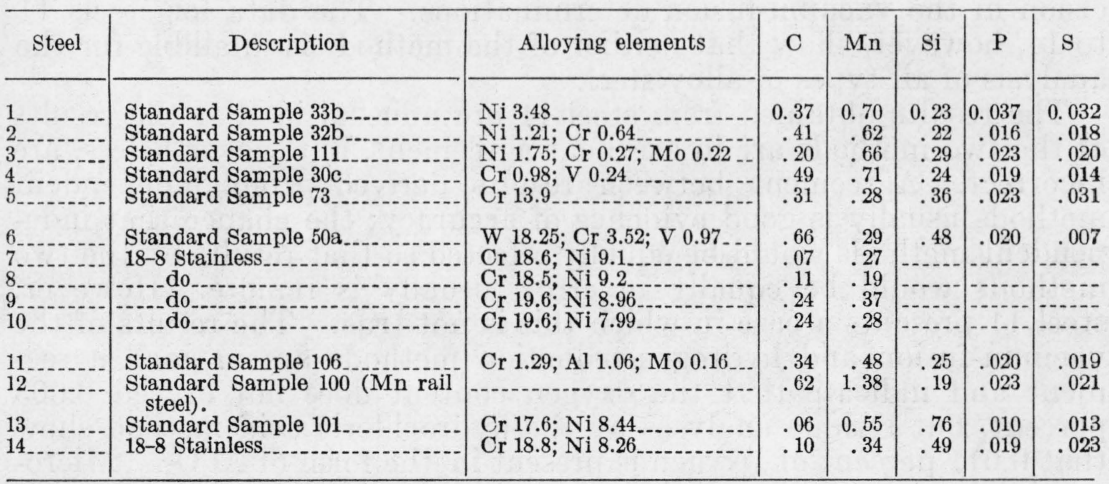

The results of the determinations of oxygen are presented in table 2 . Steels 1 to 10 , inclusive, cover a wide range of compositions, for all of which satisfactory results were obtained by both methods of analysis. In the vacuum-fusion determinations there was no evidence of interference by any of these alloying elements. The determinations proceeded smoothly and without apparent difficulty; the precision, i. e., the reproducibility of results, is fully as good as for simple steels. The accuracy of these results is confirmed by the hydrogen-reduction determinations. The agreement between the results by the two methods is very good in most cases and even for steels 2 and 6 where 
the accord is least satisfactory, the results are still in agreement within the combined tolerances of the two methods, \pm 0.002 percent for the vacuum-fusion method and \pm 0.003 percent for the hydrogen-reduction method.

TABLE 2.-Determinations of oxygen in alloy steels

\begin{tabular}{|c|c|c|c|c|c|c|c|}
\hline Steel & Type & $\begin{array}{l}\text { Oxygen } \\
\text { by vac- } \\
\text { uum- } \\
\text { fusion }\end{array}$ & $\begin{array}{c}\text { Oxygen } \\
\text { by hy- } \\
\text { drogen- } \\
\text { reduc- } \\
\text { tion }\end{array}$ & Steel & Type & $\begin{array}{l}\text { Oxygen } \\
\text { by vac- } \\
\text { uum- } \\
\text { fusion }\end{array}$ & $\begin{array}{l}\text { Oxygen } \\
\text { by hy- } \\
\text { drogen- } \\
\text { reduc- } \\
\text { tion }\end{array}$ \\
\hline $1 \ldots$ & $3.5 \mathrm{Ni}$ & $\left\{\begin{array}{c}\text { Percent } \\
0.012 \\
.011\end{array}\right.$ & $\begin{array}{r}\text { Percent } \\
0.012 \\
.009\end{array}$ & 9--....- & $19 \mathrm{Cr} ; 9 \mathrm{Ni}-.--$ & $\left\{\begin{array}{r}\text { Percent } \\
.020 \\
.020\end{array}\right.$ & $\begin{array}{r}\text { Percent } \\
.020 \\
.018\end{array}$ \\
\hline 2 & $1.2 \mathrm{Ni} ; 0.6 \mathrm{Cr}_{-}$ & $\left\{\begin{array}{l}.006 \\
.005\end{array} \mid\right.$ & $\begin{array}{l}.011 \\
.010\end{array}$ & 10 & $19 \mathrm{Cr} ; 8 \mathrm{Ni}$ & $\left\{\begin{array}{l}.018 \\
.020\end{array}\right.$ & $\begin{array}{l}.016 \\
.016\end{array}$ \\
\hline 3--- & $1.7 \mathrm{Ni}: 0.3 \mathrm{Cr} ; 0.2 \mathrm{Mo}$ & $\left\{\begin{array}{l}.004 \\
.004\end{array}\right.$ & $\begin{array}{l}.002 \\
.002\end{array}$ & & $1.3 \mathrm{Cr} ; 1.0 \mathrm{Al} ; 0.2 \mathrm{Mo}$ & $\left\{\begin{array}{l}.002 \\
.003\end{array}\right.$ & .000 \\
\hline 4... & $1.0 \mathrm{Cr} ; 0.2 \mathrm{~V}$ & $\left\{\begin{array}{l}.006 \\
.005\end{array}\right.$ & $\begin{array}{l}.007 \\
.009\end{array}$ & $12 \ldots$ & $1.4 \mathrm{Mn}$ & $\left\{\begin{array}{l}.003 \\
.003\end{array}\right.$ & $\begin{array}{l}.011 \\
.009 \\
.000\end{array}$ \\
\hline 5... & $14 \mathrm{Cr}_{--.-}$ & $\left\{\begin{array}{l}.020 \\
.018\end{array}\right.$ & $\begin{array}{l}.012 \\
.017 \\
.020\end{array}$ & 13 & $18 \mathrm{Cr} ; 8 \mathrm{Ni}$ & $\left\{\begin{array}{l}.008 \\
.009\end{array}\right.$ & $\begin{array}{l}.004 \\
.002 \\
.005\end{array}$ \\
\hline $6 \ldots$ & $18 \mathrm{~W} ; 3.5 \mathrm{Cr} ; 1.0 \mathrm{~V}$ & $\left\{\begin{array}{l}.004 \\
.004\end{array}\right.$ & $\begin{array}{l}.009 \\
.006\end{array}$ & & & & $\begin{array}{l}.005 \\
.006\end{array}$ \\
\hline $7 \ldots$ & $18 \mathrm{Cr} ; 9 \mathrm{Ni}$ & $\left\{\begin{array}{l}.011 \\
.012\end{array}\right.$ & .014 & $14 \ldots . . .$. & $19 \mathrm{Cr} ; 8 \mathrm{Ni}$ & $\left\{\begin{array}{l}.018 \\
.018\end{array}\right.$ & .015 \\
\hline & $18 \mathrm{Cr} ; 9 \mathrm{Ni}$ & $\left\{\begin{array}{l}.013 \\
.013\end{array}\right.$ & $\begin{array}{l}.014 \\
.013\end{array}$ & & & & $\begin{array}{l}.008 \\
.009\end{array}$ \\
\hline
\end{tabular}

The data for steels 1 to 10 , inclusive, therefore indicate that both the vacuum-fusion and hydrogen-reduction methods yield accurate results for samples of the compositions indicated, with greater precision in the vacuum-fusion determinations. The data for steels 11 to 14 , however, show that neither of the methods is infallible for the analysis of all types of alloy steel.

The results obtained from steel 11 are unusual in that the results of the two methods are in excellent agreement, but, nevertheless, are incorrect. Agreement between results derived from independent methods usually is good evidence of accuracy; the chance that independent methods would be equally affected so that results by the two methods would be equally in error, usually is remote. However, steel 11 presents a case in which this is not true. The results of the vacuum-fusion and hydrogen-reduction methods are in good agreement and indicate that the oxygen content does not exceed 0.003 percent, but residue analyses by the hydrochloric acid method show that 0.011 percent of oxygen is present in the form of $\mathrm{Al}_{2} \mathrm{O}_{3}$. Microscopic examination reveals the presence of alumina inclusions arranged in the usual stringer formation, together with some large inclusions, as shown in figure $1(A)$. The large inclusions, up to $0.03 \mathrm{~mm}$. in diameter, were angular in outline, suggesting a refractory, high-melting composition that was not elongated during previous hot- or coldwork. The inclusions were a light gray in color, similar to the color of $\mathrm{FeO}$. At higher magnification, the presence of black lines within the inclusion, as shown in figure $1(B)$, indicates a duplex structure, although there were no differences in the appearance of the different portions of the inclusion, nor in their response to the action of chemical reagents. In the section shown in figure $1(B)$, the white areas within the inclusion are holes or thin spots that have been polished through, 


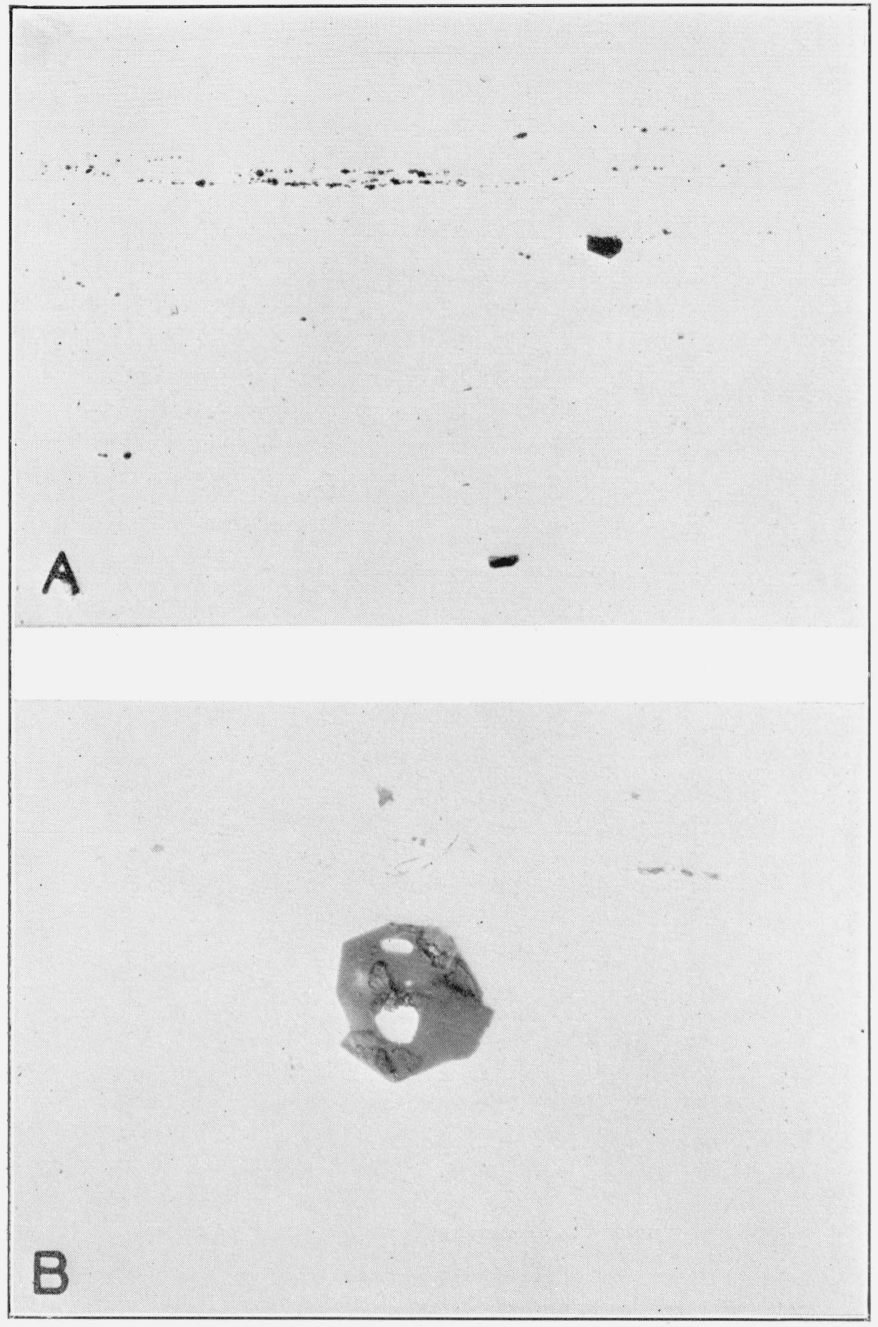

FIGURE 1.-Inclusions in steel 11.

$A$, Typical $\mathrm{Al}_{2} \mathrm{O}_{3}$ stringers and occasional large inclusions, $\times 100 ; B$, appearance of one of the large inclusions at higher magnification, $\times 500$. 


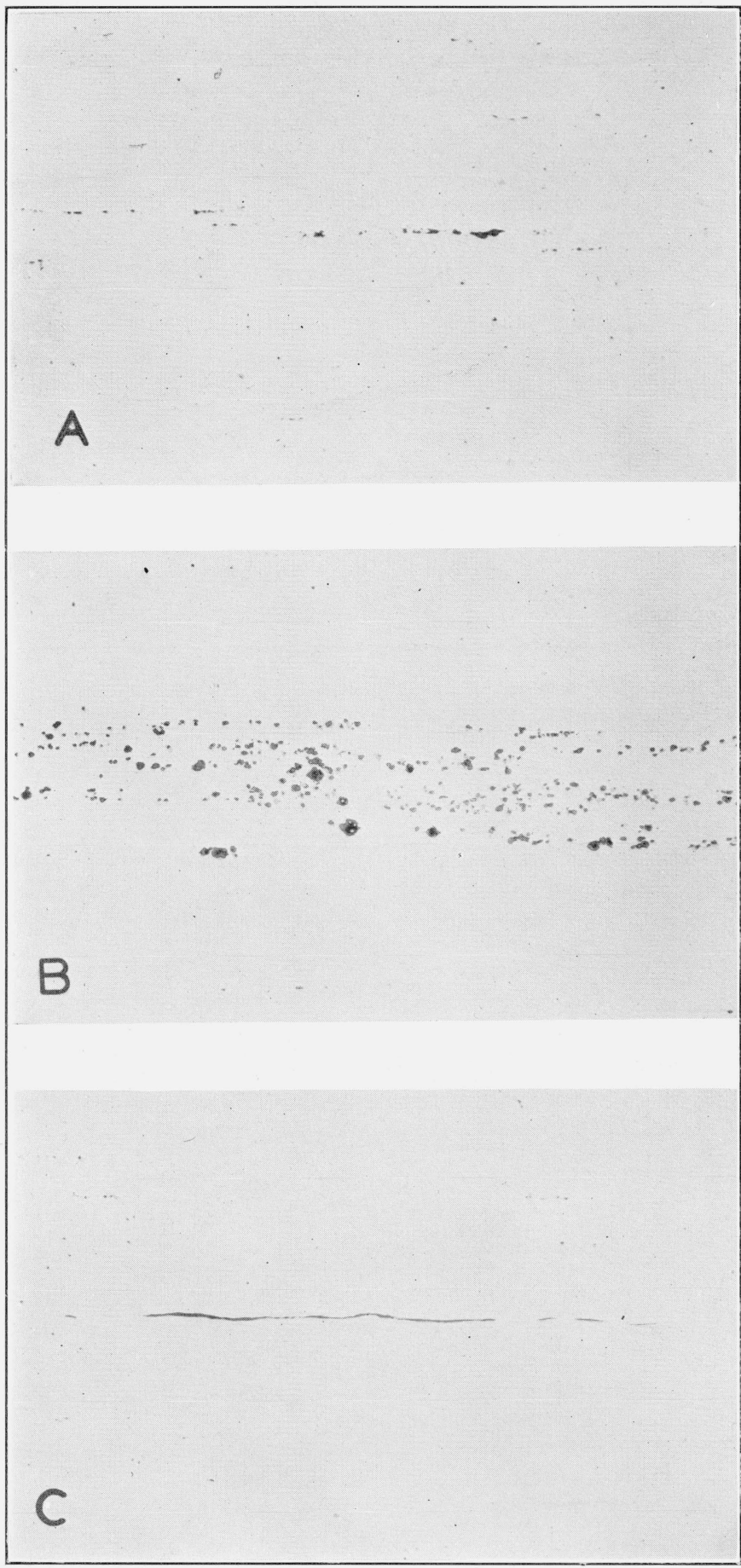

Figure 2.-Inclusions in 18-8 steels.

$A$, Typical appearance of steels 7 to 10 , inclusive, $\times 100 ; B$, inclusion band in steel $13, \times 100$; $C$, elongated inclusions in steel $14, \times 100$. 
exposing the underlying iron. Identification of the large inclusions, by means of Campbell and Comstock's procedure as modified by Wohrman [7], was not conclusive. ${ }^{2}$ They were not attacked by 10 percent nitric acid in alcohol nor by 10 percent chromic acid in water. They were slightly attacked by boiling alkaline sodium picrate, but subsequently were unaffected by a saturated solution of stannous chloride in alcohol. After a final treatment with hydrofluoric acid, which attacked the inclusions slightly, an attempt to repolish the specimen was made but was unsuccessful. The large inclusions evidently had been loosened by the various etchants and could not be retained in the specimen during repolishing.

These observations, together with the refractory composition evidenced by the failure to be elongated by previous work, suggest that the inclusions are rich in alumina, perhaps with small amounts of $\mathrm{MnO}$ and $\mathrm{SiO}_{2}$ present. Furthermore, some of the large inclusions were intimately associated with groups or stringers of typical $\mathrm{Al}_{2} \mathrm{O}_{3}$ inclusions; in one case a stringer of $\mathrm{Al}_{2} \mathrm{O}_{3}$ appeared to be a tapering tail attached to one of the large inclusions. On the other hand, the appearance of the large inclusions differed from that of the small inclusions that are generally typical of $\mathrm{Al}_{2} \mathrm{O}_{3}$. However, $\mathrm{Al}_{2} \mathrm{O}_{3}$ inclusions of this size have not been generally observed nor widely studied. It is possible that the appearance of an $\mathrm{Al}_{2} \mathrm{O}_{3}$ particle of this size would differ appreciably from the appearance of the same material in a very fine state of subdivision.

It should be mentioned that the material for sample 11, and the other samples identified in table 1 as Standard Samples, was obtained from the cores that remained after most of each billet had been removed. Obviously any segregation in the ingot would be concentrated and intensified in the core. The micrographs shown in this paper represent the waste material that was not used in the preparation of standard samples; they do not represent the structure of the material actually used in the preparation of the Standard Samples issued by this Bureau.

The explanation for the low results for oxygen in steel 11, by both methods, presumably is found in the nature and size of the inclusions. It is known that reduction of $\mathrm{Al}_{2} \mathrm{O}_{3}$, particularly in large particles, is relatively slow in the vacuum-fusion procedure and that low recoveries of oxygen may be obtained from samples that, in addition to $\mathrm{Al}_{2} \mathrm{O}_{3}$, contain appreciable amounts of volatile metals such as manganese or aluminum. The low recovery of oxygen from steel 11, by the vacuumfusion method, apparently illustrates interference by aluminum vapor coupled with slow reduction of the large particles of $\mathrm{Al}_{2} \mathrm{O}_{3}$. If particles of $\mathrm{Al}_{2} \mathrm{O}_{3}$ are reduced only slowly at $1,650^{\circ} \mathrm{C}$, in the vacuumfusion procedure, it would be expected that they would be reduced more slowly or not at all at $1,200^{\circ} \mathrm{C}$, in the hydrogen-reduction procedure. The $\mathrm{Al}_{2} \mathrm{O}_{3}$ that exists in this steel evidently is not reduced by the hydrogen-reduction procedure.

The data for steel 12 also illustrate the interference of metal vapors, manganese in this case, in the operation of the vacuum-fusion method. Although this steel presumably was killed with aluminum (the total $\mathrm{Al}$ content is 0.02 percent), residue analyses show only 0.004 percent of $\mathrm{Al}_{2} \mathrm{O}_{3}$, equivalent to 0.002 percent of oxygen. Apparently oxides

${ }^{2}$ The preparation of metallographic specimens and the identification of inclusions were conducted by G. A. Ellinger and J. S. Acken. 
other than $\mathrm{Al}_{2} \mathrm{O}_{3}$ are present in this steel and are reduced in both analytical procedures. In the vacuum-fusion procedure a secondary reaction with manganese vapor probably interfered with the recovery of the evolved oxygen, whereas the hydrogen-reduction procedure was not subject to this interference. This steel furnishes an unusual example in that the hydrogen-reduction results are higher and probably more nearly correct than the vacuum-fusion determinations.

For steels 13 and 14, both of the 18-8 type, unsatisfactory and erratic results were obtained, particularly by the hydrogen-reduction method. This is in distinct contrast to the results obtained for steels 7 to 10 , where both analytical methods yielded satisfactory results of a high degree of precision. However, microscopic examination furnishes a clue to this variation in behavior of different steels of the same general type. Figure 2(A) is typical of the appearance of steels 7 to 10 , inclusive, for which satisfactory analytical results were obtained. There are occasional oxide stringers, but most of the inclusions are very small and are uniformly distributed throughout the specimen. On the other hand, steel 13 contained broad bands of oxide inclusions, many of them of appreciable size, as is illustrated in figure 2(B). This condition could account for the low and somewhat erratic recoveries of oxygen by the hydrogen-reduction method because of slow and incomplete reduction of the large oxide particles. The values obtained by the vacuum-fusion procedure are higher and probably approximate more closely the true oxygen content of the steel.

For steel 14, the low and erratic results by the hydrogen-reduction method apparently are associated with the presence in this steel of elongated inclusions, probably silicates, illustrated in figure $2(\mathrm{C})$. It is obvious that, in the preparation of the very fine millings required in the hydrogen-reduction procedure, brittle inclusions of the type and size shown in figure $2(\mathrm{C})$ could be shattered and lost. Two of the determinations by the hydrogen-reduction method indicated 0.015 and 0.016 percent of oxygen, respectively, in fairly good agreement with the vacuum-fusion values. These two determinations probably were made on samples in which the inclusion material had been completely retained; the low and erratic values by the hydrogenreduction procedure probably result from the loss of brittle inclusion material during the preparation of the finely milled sample. In the large, solid samples used in the vacuum-fusion procedure, there is less danger of loss of brittle inclusions. The higher and more consistent results by the vacuum-fusion procedure probably are better approximations of the oxygen content of this steel.

\section{SUMMARY}

Agreement in results for oxygen in alloy steels, obtained by two independent methods of analysis, is evidence of the accuracy of the results obtained from a majority of the steels. It is known that either method, under certain conditions, may yield low results for oxygen. Consequently, if results by the two methods are not in agreement, the higher values are probably more nearly correct.

The vacuum-fusion method has been shown to yield accurate results for the oxygen contents of a number of alloy steels, representing a wide range in composition and type. Low recoveries of oxygen were 
obtained from certain alloy steels because of interference by vapors of aluminum or manganese, particularly when the steels also contained difficultly reducible oxides. The evidence of the present work is that the vacuum-fusion method is equally applicable to, and is subject to the same limitations in, the analysis of alloy steels and of simple, plain carbon steels. The presence of the common alloying elements or their oxides does not present added difficulty in the operation of the vacuum-fusion method.

The hydrogen-reduction method likewise yields accurate results for a number of alloy steels. However, the precision of this method is not as good and the range of applicability is not as great as that of the vacuum-fusion method. Low recoveries of oxygen are obtained by the hydrogen-reduction method when appreciable quantities or large particles of $\mathrm{Al}_{2} \mathrm{O}_{3}$ are present; low and erratic results may be obtained when large inclusions other than $\mathrm{Al}_{2} \mathrm{O}_{3}$ are present. On the other hand, the hydrogen-reduction procedure is not as susceptible to manganese interference as is the vacuum-fusion procedure.

\section{REFERENCES}

[1] Trans. Am. Inst. Mining Met. Engrs. 125, 246 (1937); J. Research NBS 18, 259 (1937) RP976.

[2] J. Research NBS 21,79 (1938) RP1114.

[3] Jernk. Ann. 115, 549 (1931).

[4] Trans. Am. Inst. Mining Met. Engrs. 113, 111 (1934).

[5] BS J. Research \%, 375 (1931) RP346.

[6] Trans. Am. Inst. Mining Met. Engrs. 113, 61 (1934).

[7] Metals Handbook, p. 561 (1936).

Washington, April 22, 1938. 